Article

\title{
A Holistic Analysis Approach to Social, Technical, and Socio-Technical Aspect of E-Government Development
}

\author{
Omer Gibreel ${ }^{1}$ and Ahreum Hong ${ }^{2, *}$ \\ 1 Technology Management, Economics and Policy Program, Seoul National University, Seoul 08826, Korea; \\ omar@snu.ac.kr \\ 2 Graduate School of Technology Management, Kyung Hee University, Yongin Si 1732, Korea \\ * Correspondence: arhong@khu.ac.kr; Tel.: +82-031-210-2145
}

Received: 28 September 2017; Accepted: 22 November 2017; Published: 26 November 2017

\begin{abstract}
Recently, a new trend has been emerging in understanding the differences in the implementation of ICT (Information Communication Technology) in the context of e-government between the developing and developed world. The two are broadly distinct in their characteristics of implementation due to differences in the diffusion and speed of technology patterns combined with efforts to bridge the digital divide. This leads to the objective of this paper, understanding the dynamic effects intertwining diverse aspects—social, technical, and socio-technical—on the development of e-government. However, current research still lacks a holistic perspective in comprehending how social, technical and socio-technical dimensions interact or promote the development of e-government system in a given state. This paper uses a panel dataset gathered from the World Bank, UN, and ITU databases. The research results highlight the need to look at the development of e-government through a more holistic approach rather than an atomistic single-cause approach. The results also indicate that there is no one-size-fits-all solution and a more effective e-government master plan should take into consideration the technical side of e-government development and also reflect social and, most importantly, socio-technical considerations and its holistic implication for the development of e-government systems in a given state.
\end{abstract}

Keywords: e-government; digital divide; e-participation; digital inclusion; e-service

\section{Introduction}

Ever since the dawn of history, humans have been able to formulate groups in which they were able to govern themselves and dictate rules and agreement that constitute their interaction and relationships. Governance is now entering a phase in socioeconomic development that is propelling it into the digital era in which many products and services are sold and bought online [1,2]. With this epochal shift in an ever-interconnected world, a new paradigm shift has been emerging in the field of governance and civic service. This shift, introduced by the usage of Internet-mediated tools, is empowering citizens to access government-related services online through the medium of e-government, which in turn has been defined as "the employment of the Internet and the world-wide-web for delivering government information and services to the citizens" [1]. Research in the area of e-government has focused mainly on the technological aspect of e-government. Abramson and Means narrowly classified e-government services into the following areas: Government-to-Citizen (G2C), Government-to-Business (G2B), Government-to-employees (G2E), and Government-to-Government (G2G) [3]. Studies conducted by Hiller \& Bélanger and Layne \& Lee have researched the stages of e-government development from a technical perspective $[4,5]$. As the theoretical foundation has now been laid for various types of e-government channels and 
stages of development within e-government systems, establishing a holistic view of understanding how social (e.g., literacy level and education index), technical (e.g., telecommunication infrastructure), and socio-technical (e.g., percentage of households with electricity and Internet conditions) promote or hinder the development of e-government in developing and developed nations is of outmost importance. As this area still lacks a holistic perspective necessary for understanding how social, technical and socio-technical areas influence the development of e-government system in a given state, our research focus, i.e., its object, is the study of the factors and barriers preventing the development of e-government in a given state.

The contribution of this paper is two-fold. First, this research explores the factors and barriers that lead to the development or hindrance of e-government in a given state. Second, this research presents policy implications that government agencies and policymakers may take into account before or during the process of e-government development in their respected jurisdictions. To explore and answer these questions, panel data is first gathered from the World Bank, ITU, and the United Nation dataset including 200 countries, both developed and developing, spanning a decade. Second, the countries are grouped according to four income levels: high, high-middle, low-middle, and low. Third, panel analysis testing for both fixed and random effect is performed, followed by a Hausman test, to explore the fitness of the model and determine whether to proceed with random effect or fixed effect estimations. Finally, this research explores the implication of how different selected variables affect different levels of national income followed by policy-making implications for the development of e-government in a given state.

The remainder of this paper is organized as follows. The next section provides an overview of recent developments in e-government, followed by this study's research and data collection methods. Section 3 introduces our model and factor identification as well as the selections process. Section 4 summarizes the paper by concluding our analysis and presenting future implication and conclusions.

\section{Background and Literature Review}

The emergence of e-government and its benefits have been well explored and articulated by Fountain [6], Central Issues in the Political Development of the Virtual State, in which she stated:

The significance and depth of the effects of the Internet in governance stem from the fact that information and communication technologies have the potential to affect production (or capacity) as well as coordination, communication, and control. Their effects interact fundamentally with the circulatory, nervous, and skeletal system of institutions. Information technologies affect not simply production processes in and across organizations and supply chains. They also deeply affect coordination, communication and control—in short, the fundamental nature of organizations.

Hence, e-government is not just a set of tools that assist citizens in interacting with their government but is also a tool that shift the arrangement of production, be it service or content, and even how communication is conducted between entities, leading to novel ways in which governments are able to communicate with their citizenry.

Research in e-government systems commenced with the introduction of the basic building blocks of these systems. Various researchers (e.g., Abramson \& Means and Hiller \& Bélanger) have conducted research in the areas of categorizing e-government and their services with respect to distinct social segments [3,4]. Some (e.g., Hiller \& Bélanger and Layne \& Lee) have proposed several stages for the development of e-government [4,5] and Hiller \& Bélanger have proposed a five-stage model that introduces the five stages of technological development: information, two-way communication, transaction, interaction, and finally participation [4]. Establishing the foundation to which these stages could be used by government to provide services to citizens, business, and between government entities from the initial stage of providing information through a governmental website to the last stage in which citizens play a vital and pivotal role in the development process of new contents and 
services. Chen, Chen, Huang, \& Ching have also researched the development of e-government in developed and developing countries, which are dissimilar in their development stage due to the different stages of development and implementation [7]. On the social aspect, Elbahnasawy has researched the effect of e-government system on the curbing of corruption in a given state [8] and Masiero has studied the transformation of India's biggest food security net, the Public Distribution System (PDS) into a digitalized form and its effect on combating the problem of diversion ("rice mafia") of PDS goods to the market [9]. Furthermore, several studies have been done on bridging the digital divide and the development of effective telecommunication policies for the developing world, including Howard \& Mazaheri, 2009, who studied the effect of different reforms such as privatization of markets and the effect of regulatory independence on reducing the digital divide [10], and Gibreel, Jeon, \& Yoo, who studied the effect of several development indictors including internet penetration rate and GNI per capita in bridging the digital divide in the developed and developing world [11]. Nonetheless, examining the social, technical and socio-technical dynamics that are interconnected with the development of e-government is crucial in understanding both early stage and evolutionary stage prerequisites for the development of e-government in a given state. Figure 1 explores the basic needs of the development of Internet mediated e-government systems.

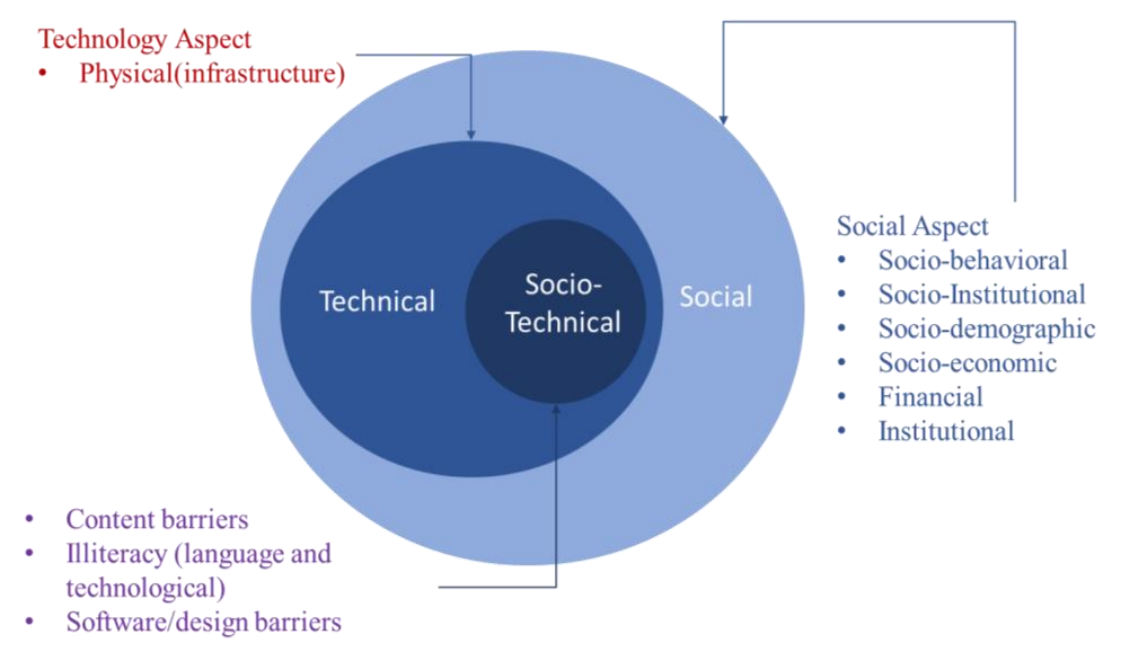

Figure 1. Nexus of technical, socio-technical, and social development of ICT.

Due to the nature of governance and how it influences many dimensions of daily life from laws enacted or amended and tax imposed, the need to examine the development of these systems from a holistic perspective is important. Examination of the social aspect in terms of education index and literacy level, the technical side such as technology infrastructure, and the socio-technical side such as level of Internet usage in a given household is important in understanding the requirements at a given stage of e-government development. Before comprehending their interaction, exploring the development of ICT in general in a given state and the factors and barriers promoting or deterring its development is advisable. Accordingly, this paper explores some of the underlying factors that affect the developing of ICT in the developing world (Figure 1).

Institutional factors and the introduction of digital means and methods into institutions increase participation rates in digital technologies and systems. For example, the availability of Internet connection and computers in public spaces such as governmental institutes and universities promotes the development of these digital systems and empowers citizens by inducing them to learn how to use them and benefit from their development [12]. This in turn advances the development of e-government services that provide services for those citizens who possess the tools and capabilities to use governmental services through online mediated systems.

Finance as a factor cannot be overlooked as ICTs and Internet usage in a given state should be affordable (i.e., within the average citizen's willingness to pay for these services) to empower them to 
cross the digital divide and enter the world of digital services and information and communication technologies [13]. The result is an environment in which IT services and products are bought and sold at reasonable prices, allowing the development of new markets and sectors and also the provision of tools by which citizen are able to interact with their government.

Regarding the literacy and content factors, the availability of local content in digital form facilitates the diffusion and usage of ICT technology. Likewise, relatively high literacy in certain world languages such as English can accelerate ICT diffusion. Another consideration is the literacy factor itself as many sub-Saharan African states suffer from high illiteracy levels that can impede widespread access and usage of information. Hence providing software systems that are customized to cater to all citizens regardless of literacy would encourage e-government service development and dissemination in a given state.

The content factor can also narrow the digital divide as information about local problems and in local languages facilitate and encourage access information that citizens both need and can read in their own language. Graham \& Hale and Stephens observed that "there is a clear and highly uneven geography of information in Wikipedia. Europe and North America are home to $84 \%$ of all articles" and "almost all of Africa is poorly represented in the encyclopedia. There are more Wikipedia articles (7800) written about Antarctica than any country in Africa or South America. Even China, which is home to the world's largest population of Internet users and is the fourth largest geographical jurisdiction, contains fewer than $1 \%$ of all geo-tagged articles" [14]. With respect to physical (infrastructure) factors, citizens must have access to the basic components of computing services, such as electrical gridlines, wired or wireless Internet connection and the primary medium of interaction, the computer itself. Related factors must also be considered, e.g., sufficient "distribution of ICT devices per capita" [12] and other indexes. These must be addressed by developing countries as many users have limited access to computers at home and must gain access to Internet services from Internet cafes.

Several socio-demographic factors are known to affect the level of ICT access, i.e., diffusion affect, such as income and GDP. Socio-economic factors likewise cannot be ignored. In certain countries, class determines access to technology. Moreover, certain countries suffer from pervasive digital exclusion and could benefit from policies designed to mitigate the concomitant adverse effects.

Relevant software design also plays a vital role in bridging the digital divide. Question Box, an organization that started in India and now operates in Africa and other parts of the world have tackled the issue that " 1.4 billion people in the world are illiterate, one fifth of the world's population, let alone the other 20 percent who can only read in their local language" and questioned "how do you reach out and engage successfully with these populations?" [15]. Farmers in India use Question Box by verbally inputting queries to obtain answers to questions regarding health, agriculture, and business. "Question Boxes give easy access to information, connecting and improving the lives of populations in areas with high illiteracy, social and technical barriers" [15].

Political obstruction should also be taken into consideration. Guillén and Suárez concluded that "democratic political regimes enable faster growth of the Internet than authoritarian or totalitarian regimes." [16]. Internet policies set in place to prevent certain actions by certain citizens have instead led to their large expansion and in turn to protests that have even uprooted governments through public uprisings. The Arab Spring provides a salient example. In Egypt, the Internet was blocked, hindering Internet usage, but Egyptians were able to find other means of accessing the Internet [17].

\subsection{Basic Strengths, Weaknesses, Opportunities, and Threats Analysis}

To further explore e-government systems, a preliminary strengths, weaknesses, opportunities, and threats (SWOT) analysis with MAXI-MAXI and MINI-MINI has been conducted to understand the strengths, weaknesses, opportunities and threats of developing e-government in a given state. MAXI-MAXI maximizes opportunities with the given strength of the introduction of e-government systems. Conversely, MINI-MINI minimizes weaknesses by understanding how threats could be avoided and resolved. Among the factors that strengthen the development of e-government in a given 
state is obviously the emergence of adequate ICT infrastructure in many countries around the world, especially the more recent advances in the developing world, notably sub-Saharan Africa $[18,19]$. Also noteworthy is the introduction of e-government services through mobile systems, a process termed mobile government or m-government leading to easy access to government services in rural and otherwise nearly inaccessible areas, according to Kushchu \& Kuscu [20]. In terms of opportunities, the emergence of mobile systems and Internet-mediated systems in the developing world [21] have helped to promote the delivery of e-government systems that in turn help to more easily provide services to citizens by evaluating their needs and developing future-oriented goals based on the data gathered by these government systems during the process of service delivery. On the other hand, in terms of weakness, development of a new legal framework is required to promote the development of new channels of information and document exchange between government and citizen and intra-government entities and thereby pave the way for the introduction of digital signature systems and public key infrastructure that build trust and reliability [22]. In terms of threat, the need to build secure and sound systems is of the utmost importance in building trust in and continuity of e-government systems.

Further analysis has been performed on an extended version of this SWOT analysis using MAXI-MAXI methods that maximize strength by harnessing the opportunities shown in Figure 2 . As several countries are now embracing new technology from telephony systems to mobile and Internet systems, we are entering a phase in which citizens own the device by which they can interact with their governments, hence the need to find facile methods to develop content. To this end, service plays a vital role in tapping into this advantage, in the same vein that it can also be deduced that, from the diffusion of these interconnected systems, governments are able to assess the needs of their citizens even more comprehensively and accurately from the data gathered and the feedback loop introduced, which in turn should logically help in building future oriented plans that are personalized according to each country or segment of the society in a given state.

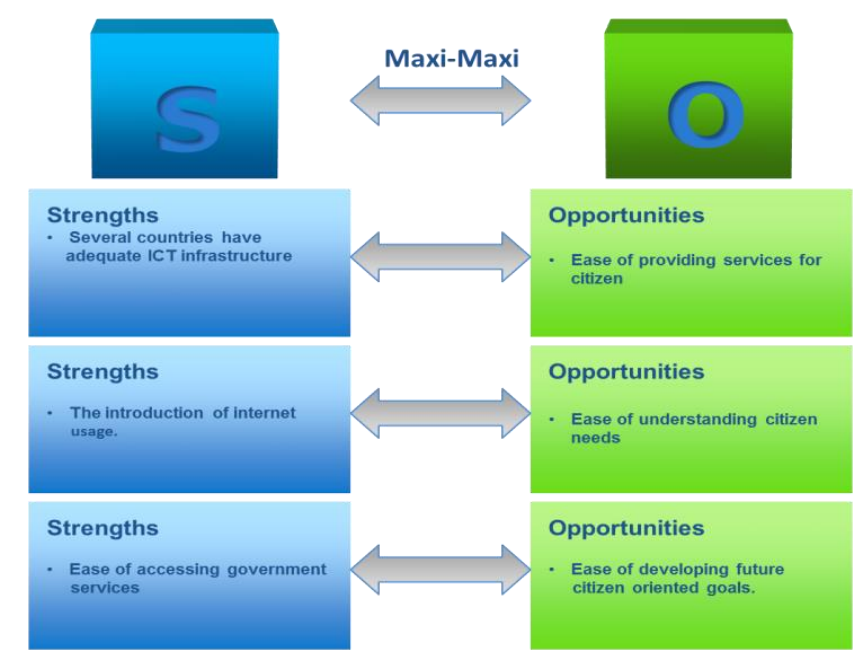

Figure 2. MAXI-MAXI SWOT analysis of e-government system introduction.

Further analysis has also been performed to extend SWOT using the MINI-MINI method shown in Figure 3, which minimizes weakness and threats. For example, one e-government weaknesses is that its development has prerequisites, notably establishment of an appropriate legal regime and specific statutes that support both public key infrastructure and digital signatures are important in the early stage of e-government development. One barrier in passing these laws is bureaucratic inertia, which hinders the formation of new identification authenticating methods for consumers using online government service systems. There is a neutral opinion concerning bureaucracy within digital government [23]. However, there is a risk that the introduction of new technology into 
the e-government system will lead to a bureaucratic process of introducing regulatory and policy legislation that could hinder innovation in technology. Theoretical Weberian bureaucratic efficiency arguments aside, in reality, this specific legislative structure could actually drive the expansion of government to ostensibly oversee but actually constrain and thwart the objectives of ICT projects. In short, there is a risk that the introduction of new technology into the e-government system will lead to a bureaucratic process of introducing unnecessary and duplicative regulatory procedures and policy legislation that could hinder technological innovation. Accessing these systems necessitates the protection of citizen privacy through enhanced security, which in turn instills trust in the system. These intertwined elements must be in place to ensure an adequate level of security for all citizens. This is not only the task of government but requires constant and consistent education of the citizenry in the safe and secure usage of online entity and personal information.

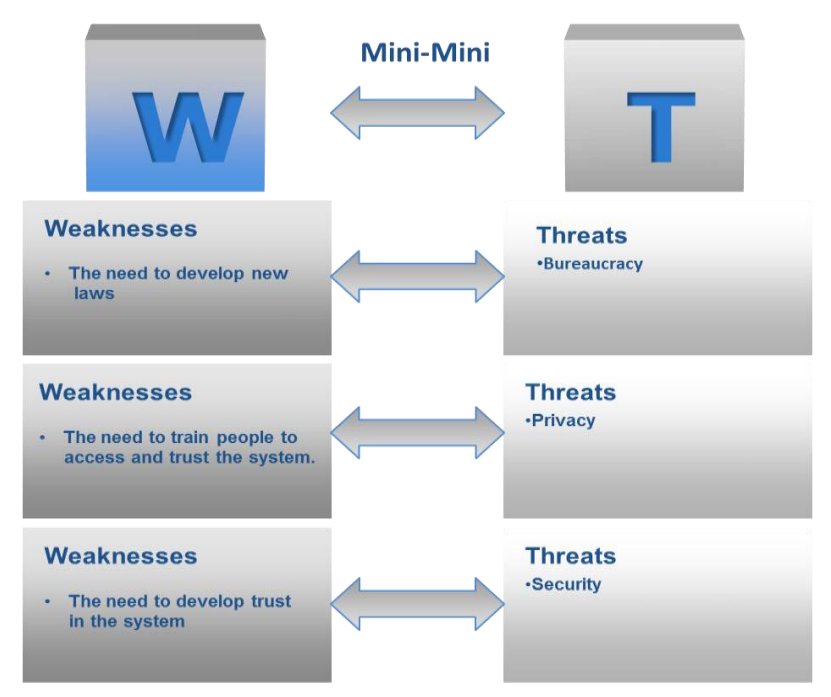

Figure 3. MINI-MINI SWOT analysis of e-government system introduction.

\subsection{Research Question and Hypotheses}

Building on this paper's research question, this paper concludes the following hypotheses:

Hypothesis 1. Social aspects has a positive relationship with e-government development.

1.1. The literacy rate impacts social development and readiness for development of e-government enabled systems.

1.2. The education index impacts social development and readiness for development of e-government enabled systems.

Hypothesis 2. Technical aspects have a positive relationship with e-government development.

2.1. Telecommunications infrastructure is positively related with development of e-government enabled systems.

Hypothesis 3. Socio-technical aspects have a positive relationship with e-government development.

3.1. Technology usage in a given household is positively related with development of e-government enabled systems.

Hypothesis 4. Increases in telecommunication infrastructure are positively related with e-government development in the long run.

4.1. Telecommunication infrastructure expansion is positively related with e-government development, at least in the long term. 


\section{Research Methodology}

To explore these hypotheses, data was gathered from ITU, World Bank, and the United Nations. The type of data gathered included panel data, the accumulated data aspects were divided into social, socio-technical, and technical, and the characteristics schema of the data was year, country and observed variables. Next, the method and test used in this research were explored to analyze the dataset.

\section{Panel Data Analysis}

Panel data analysis helps in understanding variables that cannot be controlled, observed or measured. Through this method, this study undertakes to determine the factors, such as differences between countries and across time, that influence e-government diffusion and development. This study uses ordinary least squares (OLS) method to find linear relationships between independent variables and dependent variables; the result is a line whose main objective is to minimize the square vertical distances from the line and observation point in the dataset. Furthermore this study tested for multicollinearity and correlation, which checks for autocorrelation between variables and our observed variables to omit variables that have high multicollinearity using variance inflation factors (VIF). In analyzing the dataset, this study used fixed effect Equation (1) and random effect Equation (2). Fixed effect is used to analyze the effect of variables over time and how these variables vary over time. Fixed effect is employed to clarify the relationship between independent variables and dependent variables and the outcome that they might have with the observation and across time. Each observation within the dataset has its own characteristics which may or may not affect the dependent variables. As for random effect, it differs from fixed effect in that it accounts for or assumes variation across entities to be random and not correlated. This study also uses the Hausman test as it gives a more accurate understanding in that it allows comparison between random-effect and fixed-effect estimators.

In this study, the types of data gathered were panel data. The data aspects gathered included social, technical and socio-technical in terms of year, country and observed variables, as shown in Table 1.

Table 1. Observed variables.

\begin{tabular}{|c|c|c|c|c|}
\hline Abbreviations & Category & Variables Label & Data Source & Year \\
\hline EGI & Socio-technical & E-Government Development Index & UNPACS & 2000-2014 \\
\hline TII & Technical & Telecommunication Infrastructure Index & UNPACS & $2000-2014$ \\
\hline FTS & Socio-technical & Fixed-telephone subscriptions & ITU & 2000-2014 \\
\hline PHE & Socio-technical & Percentage of households with electricity & ITU & 2000-2014 \\
\hline PHFP & Socio-technical & Percentage of households with fixed-telephone & ITU & $2000-2014$ \\
\hline PHI & Socio-technical & Percentage of households with Internet & ITU & 2000-2014 \\
\hline $\mathrm{R} 1$ & Socio-technical & Percentage of individuals using a mobile cellular telephone & ITU & $2000-2014$ \\
\hline S1 & Socio-technical & Percentage of individuals using the Internet & ITU & 2000-2014 \\
\hline SBS & Socio-technical & Satellite broadband subscriptions & ITU & $2000-2014$ \\
\hline $\mathrm{X} 1$ & Socio-technical & Wireless-broadband subscriptions per 100 inhabitants & ITU & 2000-2014 \\
\hline $\mathrm{L}$ & Social & Literacy rate, adult total (\% of people ages 15 and above) & World Bank & 2000-2014 \\
\hline $\mathrm{E}$ & Social & Education index & UNDP & $2000-2014$ \\
\hline
\end{tabular}

In Table 2, we showcase the descriptive statistics of each of our panel data variables, with their mean and standard deviation.

For the data series duration, the period 2000-2014 inclusively was selected on account of the introduction of e-government in many regions of the world. Data sources included the ITU, World Bank, and UN. Social aspect data included the adult literacy rate and education index to reflect understanding of the underlining development of social interaction and educational level of a given state. The socio-technical aspect is related to the level of technology usage in a given household, percentage of usage, and Internet penetration in a given household. It combines both the ability to use technology and its availability in a given household. The technical aspect measures the level of technological infrastructure in a given country, i.e., scoring high in the telecommunication infrastructure index. 
Table 2. Descriptive statistics.

\begin{tabular}{cccccc}
\hline Variable & Observations & Mean & Std. Dev. & Min & Max \\
\hline EGI & 2547 & 0.490469 & 0.214763 & 0 & 0.92832 \\
TII & 2547 & 0.325369 & 0.254385 & 0 & 1 \\
FTS & 2548 & 1151.516 & 710.1924 & 1 & 2386 \\
PHE & 2548 & 12.21939 & 39.58713 & 1 & 221 \\
PHFP & 2548 & 41.86578 & 100.9849 & 1 & 434 \\
PHI & 2548 & 404.3936 & 390.5425 & 1 & 1232 \\
R1 & 2548 & 11.70016 & 39.39027 & 1 & 234 \\
S1 & 2548 & 1024.427 & 614.6802 & 1 & 2085 \\
SBS & 2548 & 11.1405 & 36.05778 & 1 & 208 \\
X1 & 2548 & 120.4027 & 211.6883 & 1 & 763 \\
L & 511 & 235.0783 & 143.8551 & 1 & 486 \\
E & 1872 & 625.3819 & 402.0458 & 1 & 1359 \\
\hline
\end{tabular}

The Panel Data Analysis Method formula for both fixed effect and random effect is stated below.

- Fixed Effect Models

$$
\begin{aligned}
E G I_{i t}=\beta_{1} \text { FTS }_{i t} & +\beta_{2} P H E_{i t}+\beta_{3} \text { PHFP }_{i t}+\beta_{4} P H I_{i t}+\beta_{5} R 1_{i t} \\
& +\beta_{6} S 1+\beta_{7} S B S_{i t}+\beta_{8} X 1_{i t}+\beta_{9} L_{i t}+\beta_{10} E_{i t}+\beta_{11} T I I_{i t}+\alpha_{i}+u_{i t}
\end{aligned}
$$

- Random Effect Models

$$
\begin{aligned}
E G I_{i t}=\beta_{1} F T S_{i t} & +\beta_{2} P H E_{i t}+\beta_{3} P H F P_{i t}+\beta_{4} P H I_{i t}+\beta_{5} R 1_{i t} \\
& +\beta_{6} S 1+\beta_{7} S B S_{i t}+\beta_{8} X 1_{i t}+\beta_{9} L_{i t}+\beta_{10} E_{i t}+\beta_{11} T I I_{i t}+\alpha_{i}+u_{i t}+\varepsilon_{i t}
\end{aligned}
$$

\section{Analysis and Results}

\begin{tabular}{|c|c|c|c|c|c|c|c|c|c|c|c|}
\hline Variables & EGI & TII & FTS & PHE & PHFP & PHI & R1 & S1 & SBS & $\mathrm{X} 1$ & L \\
\hline EGI & 1.00 & & & & & & & & & & \\
\hline TII & 0.91 & 1.00 & & & & & & & & & \\
\hline FTS & -0.12 & -0.10 & 1.00 & & & & & & & & \\
\hline PHE & 0.09 & -0.01 & -0.08 & 1.00 & & & & & & & \\
\hline PHFP & 0.29 & 0.24 & -0.11 & 0.32 & 1.00 & & & & & & \\
\hline PHI & 0.55 & 0.55 & -0.04 & 0.03 & 0.21 & 1.00 & & & & & \\
\hline $\mathrm{R} 1$ & 0.30 & 0.33 & -0.01 & 0.04 & 0.34 & 0.34 & 1.00 & & & & \\
\hline $\mathrm{S} 1$ & 0.53 & 0.55 & -0.03 & 0.02 & 0.14 & 0.48 & 0.28 & 1.00 & & & \\
\hline SBS & 0.40 & 0.39 & -0.04 & 0.11 & 0.10 & 0.27 & 0.32 & 0.28 & 1.00 & & \\
\hline $\mathrm{X} 1$ & 0.30 & 0.26 & -0.08 & 0.06 & 0.17 & 0.42 & 0.30 & 0.32 & 0.36 & 1.00 & \\
\hline $\mathrm{L}$ & 0.36 & 0.30 & 0.11 & 0.11 & 0.16 & 0.30 & 0.19 & 0.22 & 0.15 & 0.26 & 1.00 \\
\hline $\mathrm{E}$ & 0.34 & 0.38 & 0.09 & 0.01 & 0.03 & 0.21 & 0.12 & 0.28 & 0.13 & 0.06 & 0.01 \\
\hline
\end{tabular}

Table 3 presents the correlation matrix revealing acceptable levels of correlation results for fixed and random effect analysis.

Table 3. Correlation matrix. 
Table 4 presents the results of our regression analysis divided into different income groups. The income group categorization approach in this research uses the method followed by the World Bank, which defines, in its data reference depository, the groups and their corresponding level of income:

Low-income economies are defined as those with a GNI per capita, calculated using the World Bank Atlas method, of $\$ 1045$ or less in 2014; middle-income economies are those with a GNI per capita of more than $\$ 1045$ but less than $\$ 12,736$; high-income economies are those with a GNI per capita of $\$ 12,736$ or more. Lower-middle-income and upper-middle-income economies are separated at a GNI per capita of \$4125. [24]

Table 4. Panel data analysis.

\begin{tabular}{|c|c|c|c|c|c|}
\hline Variable Name & $\begin{array}{c}\text { All } \\
\text { Groups }\end{array}$ & $\begin{array}{c}\text { Low } \\
\text { Income }\end{array}$ & $\begin{array}{l}\text { Low-Middle } \\
\text { Income }\end{array}$ & $\begin{array}{l}\text { High-Middle } \\
\text { Income }\end{array}$ & $\begin{array}{l}\text { High } \\
\text { Income }\end{array}$ \\
\hline FTS (Fixed telephone subscription) & -0.00839 & -0.00443 & -0.00285 & -0.0026 & -0.0432 \\
\hline $\begin{array}{l}\text { PHE (Percentage of households } \\
\text { with electricity) }\end{array}$ & $0.000442 *$ & 0.000493 & 0.000572 & 0.0000076 & 0.0242 \\
\hline $\begin{array}{l}\text { PHFP (Percentage of households with } \\
\text { fixed-telephone) }\end{array}$ & 0.000163 & 0.00019 & 0.00053 & 0.0000432 & 0.000106 \\
\hline $\begin{array}{l}\text { PHI (Percentage of households with } \\
\text { Internet) }\end{array}$ & 0.0000335 & $0.000126^{*}$ & 0.0000266 & -0.0000157 & $0.000191 * *$ \\
\hline $\begin{array}{l}\text { RI (Percentage of individuals using } \\
\text { a mobile) }\end{array}$ & -0.0000905 & 0.000551 & -0.00047 & 0.0000107 & -0.0000471 \\
\hline $\begin{array}{l}\text { SI (Percentage of individuals using } \\
\text { the Internet) }\end{array}$ & 0.00000855 & 0.0000249 & 0.0000169 & -0.00000799 & -0.0000562 \\
\hline $\begin{array}{l}\text { SBS (Satellite broadband } \\
\text { subscriptions) }\end{array}$ & $0.000494 *$ & 0.0000849 & 0.0000214 & $0.000520 *$ & -0.0000866 \\
\hline $\begin{array}{l}\text { X1 (Wireless-broadband subscriptions } \\
\text { per } 100 \text { inhabitants) }\end{array}$ & -0.0000172 & -0.0000169 & -0.00000479 & -0.00000657 & -0.00000669 \\
\hline L (Literacy rate) & 0.000113 & -0.0000558 & $0.000310 *$ & 0.000101 & -0.000176 \\
\hline E (Education Index) & 0.0000319 & 0.0000208 & 0.0000586 & -0.0000391 & 0.00000925 \\
\hline $\begin{array}{l}\text { TII (Telecommunication } \\
\text { Infrastructure Index) }\end{array}$ & $0.698^{* * *}$ & 0.0866 & $0.613^{* *}$ & $0.496^{* * *}$ & $0.614^{* * *}$ \\
\hline _constant & $0.231^{* * *}$ & $0.173^{* * *}$ & 0.127 & $0.371^{* * *}$ & $0.574^{* *}$ \\
\hline $\mathrm{R}$-sq $\left(R^{2}\right)$ & 0.801 & 0.4961 & 0.6115 & 0.5825 & 0.9364 \\
\hline N (Number of Observations) & 174 & 38 & 49 & 57 & 30 \\
\hline
\end{tabular}

\subsection{Hypothesis 1: Social Aspect}

Regarding the social aspect the research examined the following two variables: education index and literacy level. In the case of the education index when all world countries are combined, neither the education index nor literacy rate exhibits significant results. On the other hand, when groups are compared between low, low-middle, high-middle, and high income groups, the results indicate that literacy level is significant for low-middle income, i.e., (0.000310) at the $90 \%$ confidence level and $10 \%$ significance level.

Generally speaking, all countries require a certain level of literacy to enable e-government system development. This is important in that the main purpose of e-government system is to provide information that citizen can use for their personal daily life and the median of passing information is language literacy.

In the case of low income countries, the results reveal no statistical significance for literacy rate or how it plays a vital role in a country fully utilizing the benefit of e-government, but this could be an indication that in the early stage of e-government development, the need for a literate citizenry is not as pronounced as demand for the system might be in its infancy or developmental stage, and the usage of these system is not high, i.e., only used by a few literate individuals. On the other hand, as these countries move up the development spectrum, a statistical significance in the literacy rate is revealed. 


\subsection{Hypothesis 2: Technical Aspects}

As for the technical aspect, the research examined two variables: telecommunication infrastructure, e.g., development of 2G, 3G, and LTE telecommunication infrastructure, which measures the level of ICT development in a given state. For most countries, the results indicate a confidence level of $99 \%$ and $1 \%$ significance level (0.698). As countries start to develop their e-government systems, the importance of its ICT development is crucial at the initial stages. A comparison of our income level groups suggest that, at an early stage, developing countries need to consider developing basic infrastructure such as telephony, Internet and Internet mediated systems. This process must be continuous due to the aspect of ICT innovation and the extent to which the current ICT level can lead to better e-government systems such as mobile government and subsequently the Internet of Things (IoT) usage in government, e.g., tracking citizen energy usage and consumption.

Generally speaking, for successful e-government development, there is a need to first build the general infrastructure upon which an e-government system can be built. Accordingly, technical development is requisite at all national income levels (low, low-middle, high-middle and high).

\subsection{Hypothesis 3: Socio-Technical Aspect}

For the socio-technical aspect, this research examined the following variables: fixed (land-line) telephone subscription, households with electricity, household with fixed-telephone, household Internet users, individuals using mobile, individuals using Internet, satellite broadband and wireless subscription. Regarding all socio-technical aspects, Regarding all countries, the results, $(0.000442)$ at the $95 \%$ confidence level and $5 \%$ significance level, show that electrical availability is essential.

In the case of low-middle, and high-middle income countries, the results reveal that Internet usage is not significant whereas for low income there is a statistical significance $(0.000126)$ at $90 \%$ confidence level and $10 \%$ significance level, as for high income countries there is statistical significance $(0.000191)$ at the $95 \%$ confidence level and 10\% significance level. On the other hand, satellite broadband subscription is significant: (0.000520) at the $90 \%$ confidence level and $10 \%$ significance level for high-middle income.

These research results also reveal that in the early stage of development basic technologies such as mobile telephony and basic internet access are required but at later stage the need for electricity grows due to the expansion of electrically powered devices. The results also show that the shifting importance of electricity plays a vital role in building a network state that promotes the development of e-government. This in turn results in indirect mediated effects on other factors that support the development of e-government in a given state.

\subsection{Hypothesis 4: Increase in Telecommunication Infrastructure Is Positively Related with E-Government Development}

As for the telecommunication infrastructure hypothesis, there is a need for continuous development for all income group as all types of technological development in e-government require telecommunication infrastructure to support the demand of its citizenry. This can be seen in the development stages of any society that is promoting the development of a network society. First, building basic infrastructure such as telephone is crucial. Second, the Internet that stems from using modem-enable systems that are built upon wired telephone lines is introduced. Third, and in parallel to overall Internet development, the introduction of mobile telephony is also developed at the same time. The fourth stage resembles a middle stage of higher bandwidth and better Internet speed, leading to the last stage of Internet-mediated systems such as Internet of Things (IoT) and finally Internet of Everything (IoE). This resembles a cycle of continuous trends in ICT development due the aspect of technological innovation characteristics. 


\section{Discussion and Conclusions}

In conclusion, this research analyzed a panel data set from over 200 countries, spanning over 10 years, to understand the technical, socio-technical, and social aspects of e-government development in a given state. The research then developed four major hypotheses, three of which examined the short term development of three major (social, socio-technical, and technical) aspects. The fourth hypothesis examined the development of ICT infrastructure over the long term among different groups of countries.

The results reveal that in terms of social aspect, the literacy level has positive and significant effects on the development of e-government readiness for low middle-income countries, but consideration should be taken in the development and provision of these e-government services. Governments should consider the level of literacy rate within a given state and provide systems and services that overcome these barriers. Such systems and services could come in the form of voice enabled systems or graphical user interfaces that assist the illiterate in accessing information and government services online. Other social factors could come in the form of impairment such as vision impairment or locomotor impairment; hence, government should establish legal mechanisms that empower social inclusion of these marginalized groups that are in dire need of access to government services. Second, as for the technical aspect of development (Telecommunication Infrastructure Index), the results reveal a positive coefficient (0.698) that for most countries has a confidence level of $99 \%$ and $1 \%$ significance level. This reveals that at all stage of development there is a need for investment in ICT infrastructure but the investment varies across technologies from basic ICT technical development, such as $2 \mathrm{G}$ and 3G, to Long Term Evolution (LTE). As for the third (socio-technical) aspect, in the case of all countries, the results show that electricity is requisite: (0.000442) at the 95\% confidence level and 5\% significance level. In the case of low-middle and high-middle income countries, the results show that the development of Internet usage is not significant, but for low income countries, there is a statistical significance (0.000126) at $90 \%$ confidence level and $10 \%$ significance level, suggesting that an earlier stage of a country development, the availability of internet access within a given household promote the development of e-government. On the other hand, for high income countries there is a statistically significance result (0.000191) at the 95\% confidence level and 5\% significance level. Satellite broadband subscription, however, is important: $(0.000520)$ at the $90 \%$ confidence level and $10 \%$ significance level.

In conclusion, this research examined the external factors that could promote e-government readiness in a given state, thereby shedding light on the need to investigate the development of e-government from a more holistic perspective that further elucidates the development of e-government beyond the mere technical need of a given country to consider the social and social technical imperatives as well. Hence, as governments continue to develop their internet mediated government system, there is a need to localize these government services by taken into consideration social aspects such as the illiteracy rate, or even technical aspects such as the need to invest in infrastructure for the public to access e-government services when considering the development of e-government services in the first place. Concerning the limitation inherent in this research, more factors reflecting technical and social aspects could be added and analyzed to elucidate and explicate even further how they could assist in developing e-government policies and systems in a given state. Future research is recommended in developing a more nuanced e-government readiness index than the current one by integrating all three aspects and developing a more holistic e-government readiness index. Developing an e-government master plan that incorporates the technical aspects and the social and the socio-technical aspects will assist in promoting the development of an effective and efficient e-government master plan for the benefit of a given state and those it purports to serve.

Author Contributions: O.G. and A.H. conceived and designed the experiments; O.G. and A.H. performed the experiments; O.G. and A.H. analyzed the data; O.G. and A.H. contributed reagents/materials/analysis tools; O.G. and A.H. wrote the paper.

Conflicts of Interest: The authors declare no conflict of interest. 


\section{References}

1. United Nations. United Nations E-Government Survey 2014: E-Government for the Future We Want; United Nations Pubns: New York, NY, USA, 2014.

2. Gibreel, O.A.I.; AlOtaibi, D.A.; Jeon, S.; Yoo, B. Will Insta-Business Be the Electronic Contemporary Bazaar?: An Exploratory Analysis on Electronic Commerce in Kuwait; ACM Press: New York, NY, USA, 2015; pp. 1-6.

3. Abramson, M.A.; Means, G. E-Government 2001; Rowman \& Littlefield: Lanham, MD, USA, 2001.

4. Hiller, J.S.; Bélanger, F. Privacy Strategies for Electronic Government; The IBM Center for the Business of Government: Washington, DC, USA, 2001.

5. Layne, K.; Lee, J. Developing Fully Functional E-Government: A Four Stage Model. Gov. Inf. Q. 2001, 18, 122-136. [CrossRef]

6. Fountain, J.E. Central Issues in the Political Development of the Virtual State. In The Network Society: From Knowledge to Policy; Center for Transatlantic Relations: Washington, DC, USA, 2005; pp. 149-169.

7. Chen, Y.N.; Chen, H.M.; Huang, W.; Ching, R.K. E-Government Strategies in Developed and Developing Countries: An Implementation Framework. Sel. Read. Glob. Inf. Technol. Contemp. Appl. 2008, 14, 327.

8. Elbahnasawy, N.G. E-Government, Internet Adoption, and Corruption: An Empirical Investigation. World Dev. 2014, 57, 114-126. [CrossRef]

9. Masiero, S. Redesigning the Indian Food Security System through E-Governance: The Case of Kerala. World Dev. 2015, 67, 126-137. [CrossRef]

10. Howard, P.N.; Mazaheri, N. Telecommunications Reform, Internet Use and Mobile Phone Adoption in the Developing World. World Dev. 2009, 37, 1159-1169. [CrossRef]

11. Gibreel, O.; Jeon, S.; Yoo, B. An Intercountry Analysis on the Factors and Barriers to Internet Accessibility. In Proceedings of the PACIS 2013, Juje Island, Korea, 18-22 July 2013.

12. Wilson, E.J. The Information Revolution and Developing Countries; MIT Press: Cambridge, MA, USA, 2004.

13. Hilbert, M. When Is Cheap, Cheap Enough to Bridge the Digital Divide? Modeling Income Related Structural Challenges of Technology Diffusion in Latin America. World Dev. 2010, 38, 756-770.

14. Graham, M.; Hale, S.; Stephens, M. Geographies of the World's Knowledge; University of Oxford: Oxford, UK, 2011.

15. QuestionBox. What We Do. Available online: http://www.questionbox.org/overview/ (accessed on 6 November 2015).

16. Guillén, M.F.; Suárez, S.L. Explaining the Global Digital Divide: Economic, Political and Sociological Drivers of Cross-National Internet. Soc. Forces 2005, 84, 681-708. [CrossRef]

17. Hopkins, C. Complete Internet Blackout in Egypt (Updated). Available online: http://readwrite.com/2011/ 01/28/complete_internet_blackout_in_egypt (accessed on 11 December 2014).

18. ICT Initiatives-African Development Bank. Available online: http://www.afdb.org/en/topics-and-sectors / sectors/information-communication-technology/ict-initiatives / (accessed on 30 June 2015).

19. Song, S. Sub-Saharan Africa Undersea Cables in 2010-Take 7; Many Possibilities. Available online: http:/ / manypossibilities.net/2008/09/sub-saharan-africa-undersea-cables-in-2010-2 (accessed on 5 January 2008).

20. Kushchu, I.; Kuscu, H. From E-Government to M-Government: Facing the Inevitable. In Proceedings of the 3rd European Conference on E-Government, MCIL Trinity College, Dublin, Ireland, 3-4 July 2003; pp. 253-260.

21. How The Future of Mobile Lies in the Developing World I TechCrunch. Available online: http://techcrunch. com/2012/05/27/mobile-developing-world/ (accessed on 30 June 2015).

22. Nash, A.; Duane, W.; Joseph, C. PKI: Implementing and Managing E-Security; McGraw-Hill, Inc.: New York, NY, USA, 2001.

23. Patrick Dunleavy. Democracy, Bureaucracy and Public Choice: Economic Approaches in Political Science; Routledge: London, UK; New York, NY, USA, 2006.

24. World Bank. Country and Lending Groups. Available online: http://data.worldbank.org/about/countryand-lending-groups (accessed on 30 September 2015).

(C) 2017 by the authors. Licensee MDPI, Basel, Switzerland. This article is an open access article distributed under the terms and conditions of the Creative Commons Attribution (CC BY) license (http:/ / creativecommons.org/licenses/by/4.0/). 